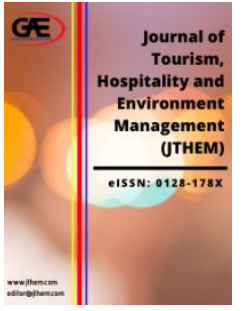

\author{
JOURNAL OF TOURISM, \\ HOSPITALITY AND \\ ENVIRONMENT MANAGEMENT \\ (JTHEM) \\ www.jthem.com
}

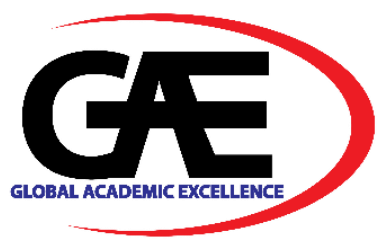

\title{
EXPLORING SAUDI REASONS FOR ECONOMIC REFORMS AND NEED TO STUDY THE SOCIAL IMPACT FOR ITS SUCCESS
}

\author{
Masood Ahmed ${ }^{1}$ \\ 1 Department of Business Administration, Jazan University, Jazan KSA \\ Email: dr.ahmed.masood@gmail.com
}

\begin{abstract}
Article Info:
Article history:

Received date: 11.03 .2021

Revised date: 21.03 .2021

Accepted date: 11.04.2021

Published date: 10.06.2021

\section{To cite this document:}

Ahmed, M. (2021). Exploring Saudi Reasons for Economic Reforms and Need to Study the Social Impact for Its Success. Journal of Tourism, Hospitality and Environment Management, 6 (23), 10-21.
\end{abstract}

DOI: 10.35631/JTHEM.623002.

This work is licensed under $\mathrm{CC}$ BY 4.0

\begin{abstract}
:
Many countries are raising questions about the intentions behind Saudi reforms. The low oil prices in 2008-09 were the awakening call for Saudis, and later in 2014, it became the reason to look for an economy that is less dependent on oil. The article studies the initiated social reforms and the social impact of foreign cultural activities. It scrutinizes Saudi society under the social exchange theory and looks for the positive and negative effects of cultural exchanges. The paper also considers the COVID-19 situation in KSA as it has broken the chain of cultural events planned all over the country to promote tourism and improve the image of KSA.
\end{abstract}

Keywords:

Reforms, Tourism, Oil Economy, Employment, Governance Indicators, Welfare

\section{Introduction}

The world as the observant, Saudi Arabia, is reforming itself. Many countries are raising questions on the intentions behind reforms, with this intention scrutinizing each step minutely. Rationally speaking, Saudis are not compelled to reform. Undoubtedly they can carry the same economic and social life for many more years, seeing that the world does not have enough bargaining power against the oil-rich country. Any outside interference will create chaos over oil prices without a doubt put the friendly and fruitful relationship with the US at risk, which is not likely to happen. Then why KSA choose to have social and economic reforms. The 


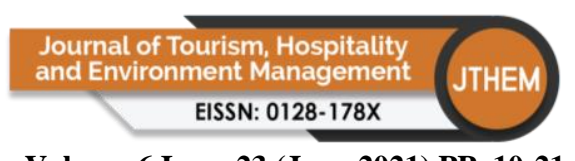

Volume 6 Issue 23 (June 2021) PP. 10-21 DOI 10/35631/JTHEM.623002

answer is the realization that the low oil prices will play havoc on their trillion-dollar economy. Forthwith they can not sustain the standards in the absence of reasonable oil prices.

In truth, the young generation is aware of the circumstances, resources and challenges that the country faces today. With this in mind, they want to change the image. They are more demanding in utilizing the available means, namely providing better education, employment and health facilities. They want to grow out from oil dependencies additionally like to contribute in other fields. The research evaluates the Vision 2030 document prepared by the Saudi Government importantly marketed as the growth plan for Saudi reforms.

\section{Literature Review}

The research article evaluates the Saudi Government Vision 2030 document, which describes its future course of action and objectives set by the Government to be achieved before 2030 . (Triki, 2019) His research analyzed the religious tourism in KSA, focussing on Haj and Umra and relating it with Saudi vision document. To understand the reforms' social impact, the social exchange theory (Emerson, 1976) is beneficial in explaining the Saudi invitation to selected cultural themes and sporting events under the reforms, whereas (Mosier, Elhadary, Elhaty, \& and Safaei, 2020) discuss the psychological impact especially in case of closing the holy shrines in the pandemic. Further social representation theory (Moliner, 2012) where host society shares social knowledge towards the external visitors, its application in Saudi case include religious flavour (Eid, 2019) where Islamic religious events of Haj and Umra is used to spread new social and religious reforms and create a new Saudi identity.

The paper felt the need to improve the scope of social representation as a tool for studying social impact. It supports socio-economic bonding by relating it with the economic direction where the dependency on oil revenue is inversely related to social reforms, motivational factors (Mansour \& Mumuni, 2019), considering that education, employment and gender equality directly contribute to economic growth. The present reforms will push for an increase in nonoil revenue and require substantial education, employment, and fair gender representation hence have a significant social impact on the present society.

The paper considers Growth machine theory (Madrigal, 1995) a tool to evaluate a citizen response and acceptance of an event. Large scale acceptance will indicate a socially acceptable impact and incorporation of external influence in the local culture. (Ahmed Osman Ibrahim, 2021) also shares the insight into the research related to religious tourism and other venues open for exploration providing economic opportunities. (Ibrahim, 2021) and (Hassan, 2020) work explores the regional tourism opportunities in Hail Region and Al-Ahsa city and how Saudi Commission for Tourism \& National Heritage (SCTH) promotes tourism.

The paper also considers the world governance indicators proposed by (Kraay, 2018) and the KSA position. Secondly, the article evaluates the KSA position in world development indicators forwarded by the World Bank. The Saudi claims were substantiated by reforms initiated by the Government and reported by the news media. The article evaluates Saudi reforms against its intention to move away from oil dependence and grow its economy (Jamel, 2020) in a broader way satisfying the long term objective of full employment for Saudi citizens and self-dependence in critical areas. 


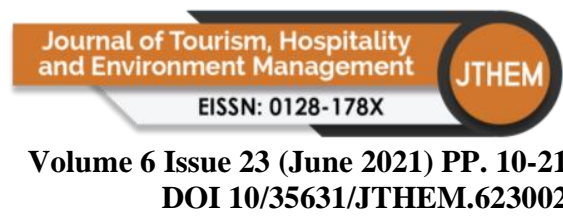

\section{Methodology}

The research article is a secondary analysis of the available data. The focus is on critically analyzing the structured steps of the Saudi reforms' notwithstanding their social consequences and their intention to lessen the oil dependency, and how COVID-19 is derailing the reforms. The research begins with the identification of the components of social impact. The three theories, Social Exchange Theory, Social Representation theory and Growth Machine theory, substantiate the purpose.

Social exchange theory is promoted by Homans (1958) under theories of social behaviour, where social exchange involves benefits to each party. It is explained as exchanging activity through social interaction, either tangible or intangible, such as having reward or cost attached to it. Social and economic benefits differ fundamentally (Nunkoo, 2016), while economic benefits are contractual, whereas social benefits are voluntary and relate to future adaptation. Social benefits are also uncertain and depend on the host absorbing all or part of an exchange.

Social exchange theory helps explain the role of cultural adaptation where general acceptance of values, financial benefits, and satisfaction derives from the enhancement of social status by acceptance of guest offerings as a reward. It has a profound and long-lasting impact on the host society. On the same note, cost includes the negative outcome of exchange where unwanted features enter a community that cost time, money and local values and leads to corrupt practices.

Social representation theory denotes the host society's ability to create and spread social knowledge of an external event or external visitors. The theory helps analyze how groups and individuals transform themselves during interaction and communicate their systems of knowledge, beliefs and opinions particular to a culture (Moliner, 2012).

Growth machine theory is vital to understand how large-scale social acceptance of an event brings positivity and calmness with minimum resistance (Zhang, 2014). In contrast, large opposing groups' presence requires restructuring policies to promote social exchanges between different parties.

During the comparative analysis of (Saudi Vision 2030) document, the Vision 2030 document is compared with the World Development Indicators given by the World Bank. The article stresses the Saudi Government's present position and steps taken towards the vision document's goals reported in the media. Social and economic changes are assessed, and their repercussions are studied over the Saudi culture. The article highlights the need to support strategic reforms and their positive effect on other countries and the Muslim population. The article explores possible outcomes and how reforms are strategically crucial for economic development and global peace.

\section{The Social Impact of Saudi Reforms}

"If you do not like your image, stay away from the mirror" this no longer valid for New Saudi Arabia as it implements social and economic reforms. Still, it is not easy to change an image meticulously built over a long period of a primitive society that believes in Islam's extreme view. Nonetheless, that precisely present leadership in KSA is trying to achieve. Saudi Arabia is working hard to accept the challenges they face today and moderate its approach to solving them. 


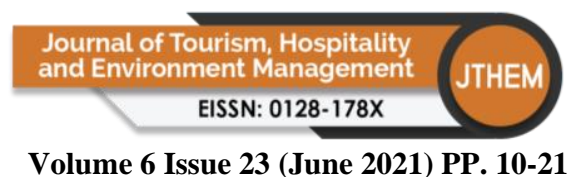

Volume 6 Issue 23 (June 2021) PP. 10-21

DOI 10/35631/JTHEM.623002

Recently famous singer-artist Mariah Carey, Janet Jackson, Andrea Bocelli and K-pop group Super Junior performance in Saudi Arabia create a sense of change in Saudi society. WWE Crown Jewel event that takes place includes women wrestlers Natalya and Lacey Evans, which mark a significant shift in how Saudi's view women.

Shows like "Bazzar" by Cirque du Soleil in Riyadh where Lauren Joy Harley plays the floating woman enjoyed by the vast spectators. Multiplexes now alluring people to relish movies is another step for people's freedom - not long before people enjoy movies in their home using a satellite dish or internet. Things are changing, and people with extremist views may be perturbed, and it is not easy for any government to control such hidden elements, seeing that it is more critical to evaluate the social impact of events. It is necessary to understand how foreign culture will affect the quality of life, challenge the prevailing meaning of subjective well being and generate social capital that incorporates foreign cultural elements.

The positive and negative changes the population will integrate due to foreign culture exposure will change their lives. The inclusion of social impact indicators encompasses three essentials: the impact on the quality of life, change in subjective well-being, and social capital development.

Quality of life represents the precise conditions in which a population lives, exposure to events denotes the higher quality of life brings in desire for improvement. Factors like the freedom to work and entertainment opportunities, accumulation of wealth, material things, and access to healthcare are few factors used to evaluate life quality.

On the other hand, subjective well-being is the state of mind coupled with the measurement of happiness, and it is quite possible that even with low quality of life, a person feels happy and satisfied. Subjective well-being is an essential factor in studying in Saudi society as Islamic principles and laws control the country; therefore, under Islamic principles, material well-being is less important than the disciplinary character and the highest form of moral upbringing. The high moral values and discipline in life leave little space for external influence for a pious saul.

On the contrary, young and restless populations seek means to combine worldly possessions in the background of Islamic education moreover look for a middle path where they are par with the rest of the world. The struggle is between the population who believe in the old and disciplined approach; on the other hand, the new and more resilient who wants to work hard to enjoy the lifestyle and seek happiness in proud possessions.

Social capital development is required where social relationships improve understanding and trust between the community cultural exchanges. More interest and information an event promotes, more is the chances of its success, and fewer will be unhappy clusters than the happy clusters (Growth Machine Theory). Ultimately it is the acceptance of an event by the society at large that signifies its success.

Vision 2030 seeks to achieve positive social impact from its foreign cultural and sports events. The focus is on generating future economic benefits by creating employment opportunities, developing recreational facilities and infrastructure, therefore, stimulating demand for products related to living standards. Similarly, it provides more entertainment opportunities where 


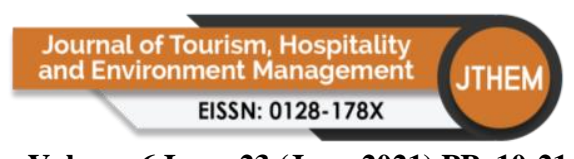

Volume 6 Issue 23 (June 2021) PP. 10-21

DOI 10/35631/JTHEM.623002

people are engaged in many exciting activities. Another objective of organizing cultural events is to enhance the country's image as a tolerant and progressive one, where foreign cultural events are welcomed and doors are opened for others to observe rich Saudi culture and heritage.

The Saudi authorities need to be aware of the cost of negative impact before permitting the events. It is the awareness of authorities that minimizes the negativity. Factors like damage to the natural environment, noise pollution, litter, rowdy behaviour, overcrowding and traffic congestion can be controlled by proper planning. However, long term impact may include an increase in the cost of living. Consequently, an increase in the crime rate requires an in-depth study of each social event and its impact on society.

For Saudis, the progressive steps result from an ordinary youth's internal distress, and it is also an outcome of information available under current affairs, availability of choices to fulfil desires backed by adequate purchasing power.

Nevertheless, the opportunities are hiding in the challenges. Accordingly, Saudis want to gain from it by reducing oil dependency and developing an economy competitive enough to accept future challenges and efficiently utilize the existing resources. In his address, the Prince emphasis on Islamic constitution and moderation in its method of adaptation. The steps are for real, and the world is witnessing a push in social and economic reforms. November 2019 witnessed the first major economic shift when Aramco's public issue opens, turning the company into a global industrial conglomerate and transforming Public Investment Fund into the world's largest sovereign wealth fund.

\section{Is This The End of The Oil Economy?}

Saudi Arabia has the largest oil production capacity, with almost one-fifth of the oil reserves under its boundaries. For KSA, oil shocks are the reason behind its rapid progress in 1973-74 oil prices increased by more than $200 \%$. During that time, KSA's GDP also increase in almost the same ratio from SR 53,047 million riyals to 159,276 million riyals. During the second oil price shock $1978-79$, KSA GDP increased by $38 \%$, when oil prices increase by $24 \%$. Later at the time of the Iraq war, KSA's GDP increased by $13 \%$, and in the fourth oil shock, the surge in oil prices in 2003 till 2008 boost the Saudi economy by almost 16.7\%, and during this, the Saudi economy reaches 1.7 trillion economic milestones (Algahtani, 2016).

The fifth oil shock was the eye-opener for Saudis in 2008-09, where oil prices drop by 38\%, causing a $21.8 \%$ decline in Saudi GDP numbers. Since then, the Saudi growth story is facing hurdles, and their dependency on oil proving to be costly as it comprises almost $80 \%$ of their export revenue, and with ups and downs in the oil prices, their economic planning also sufferers by the same rate. The rise in oil prices is the reason behind the employment figures (Jamel, 2020). The Saudi population will benefit from rapid development and a rise in their income, attracting many expatriates, providing various services, and contributing to the Saudi development story. The reverse is true when the oil prices start their decline, employment slows down, and the Government realize the need for economic reforms that include developing industries other than oil industries (Tarek Tawfik Yousef Alkhateeb, 2017).

The World Bank expects the GDP growth to be over 2\%, and Saudi plan is to increase non-oil exports percentage and increase revenue from the present SAR 163 billion to SAR 1 trillionfor this, the Public Investment Fund's Assets will go up from SAR 600 billion to over 7 trillion. 


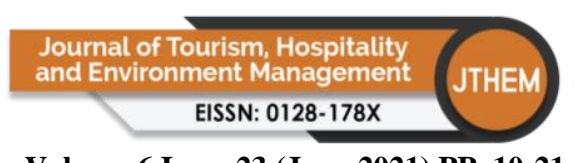

Volume 6 Issue 23 (June 2021) PP. 10-21

DOI 10/35631/JTHEM.623002

The reforms expect to attract FDI from the current level of $3.8 \%$ to over $5.7 \%$ of GDP, and Saudis aim to increase private sector contribution in the economy from the current $40 \%$ of the GDP value to get it past 65\%. (Saudi Vision 2030)

The Government is facing a young and restless population with an unemployment rate of $11.6 \%$ (Saudi Vision 2030) which they like to reduce through their National Labour Gateway (TAQAT) by establishing the sector council and intrusting them to create the necessary marketable skills and knowledge that will be in demand soon.

The belief that Saudis depend on the expatriate's population for their progress is partially true as it employs a vast population of expatriates (34.14 million WB data). On the other hand, the KSA approach is quite different from the top expat-friendly countries like Qatar, UAE, Kuwait, Jordan and Singapore. While UAE opens its market for the expatriate population and a friendly investment environment, KSA has not done so. KSA uses oil money to develop infrastructure with expatriates' help; they only employ doctors, technicians, engineers and university and school teachers, and low skill workers for manual labour. Present investment in human resources are ready to reap benefits, and their young generation is ready to take over. The Government is systematically reducing expatriates number in the fields where they feel Saudi youth has garnered sufficient expertise.

Public sector reforms include a proposal to train government employees (approx.500,000) using distance learning to generate skills needed to boost productivity. It is an ambitious step as it will bring in accountability and promote best practices in the government sector.

The retail sector is another area where the Government aims to increase Saudis employment. Currently, the sector employs 1.5 million workers, but only 0.3 million Saudis (Saudi Vision 2030) are working. The sector has a potential growth rate of more than $10 \%$. To exploit the potential, the Government decided to limit jobs in mobile shops only for Saudis. Similarly, no more dentist visa for foreigners as a sufficient number of Saudi dentists are available. In Saudi universities, the foreign staff is under scrutiny. Every year they are replaced by Saudi faculties who are joining after completing their education. In the education sector, visas are not readily available for non-PhDs as they are no longer required unless they belong to the technical field and justified by the management.

Government Nitaqat programme (Ahmed, 2016)categorized companies based on the number of Saudis they employ, under it companies benefit when Saudis are sufficient in number and punished if Saudis are less than the prescribed limit. The private sector expatriate workers are sending their family back as the Government decided to impose residency permit fees on expatriates family members in July 2017. It starts from SAR 100 per month per family member and doubles with each coming year. In 2020 it reached its maximum level. The decision put a substantial economic burden on expatriates, and for many, it is unviable to keep their family members inside the Kingdom.

The Government committed itself to increase women participation in the workforce and aims a modest increase from the present 22\% to 30\% (Saudi Vision 2030). The government decision to promote women in employment and forcing the private sector to open the door for them is now noticeable in the society where females are now working in malls and hospitality businesses. Issuing licenses to females and letting them drive is a welcome move appreciated 


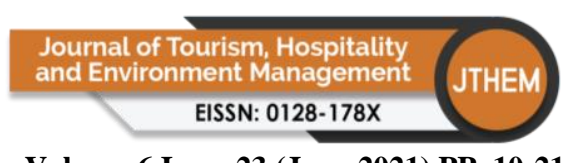

Volume 6 Issue 23 (June 2021) PP. 10-21 DOI 10/35631/JTHEM.623002

and recognized worldwide, and even critics judge it as a significant initiative towards a more free and developing society.

The recent annual Forbes list of Powerful Businesswomen in the middle east has three women from Saudi Arabia in the top five (Arabnews- $5^{\text {th }}$ Feb 2020). All three belongs to the financial sector, associated with banks and Saudi Share market. It is interesting to note that these ladies with degrees from world-renowned institutes and years of experience belong to a country that recently permitted women to drive.

Saudi women's success proves education framework and promotion, including foreign education opportunities for deserving male and female candidates, is gratifying, and with reforms, expectations are soaring.

Saudis are reaping the benefit of oil and are fortunate enough to increase their average household income by 75\% (MaKinsey \& Company Report, 2015) due to the sharp rise in oil prices during the 2003-2013 period. The period also saw the creation of 4.4 million jobs in which Saudis took 1.7 million jobs. Vision 2030 aims to achieve better results without depending on oil revenues, and its focus is on modernizing society without diluting the Islamic principles.

Today, 1.8 billion Islamic followers or $24.1 \%$ of the total world Muslim population, perform their prayers in the direction of Holy city Makkah situated in KSA. Before the oil riches, the religious pilgrimage was the primary source of income for the country; even today, it aims to increase the number of faithful visitor's from 8 million to 30 million annually (Saudi Vision 2030).

Arab news reports that economists predict that Haj and Umra's revenue is expected to exceed $\$ 150$ billion by 2022 . The aim is to accommodate 30 million Haj pilgrims and Umra performers by the year 2030 (Triki, 2019) supports the arguments in his research and (Eid, 2019) research highlights the satisfaction level that foreigners demand during their holy journey. It is also believed that the sector is ready to provide at least 100,000 jobs to Saudi citizens. The government initiative to develop infrastructure and tourist destination in other cities to take advantage of religious tourism unquestionably attract them to other places is of strategic importance.

The new approach is to promote tourism along with religious pilgrimage. It is spending money on the development of heritage sites, promoting the rich and beautiful coastline of Farsan Island and other seashores in different cities (Hassan, 2020), and orchestrating various activities to promote tourism (Ibrahim, 2021). The approach aims to attract foreigners, previously restricted to two holy cities, and now they are free to travel in other cities and spend money. Second, wealthy Saudi citizens (Mansour \& Mumuni, 2019) who enjoy holidays in other countries can enjoy the same facilities and amusement means in their own country. In both cases, it is an economic gain for the country.

\section{How Various World Indicators Measure KSA?}

KSA is a peaceful country governed strongly by its ruler under the Islamic constitution. Islamic constitution promotes social harmony through the purity of human relationships, forbid illegal 


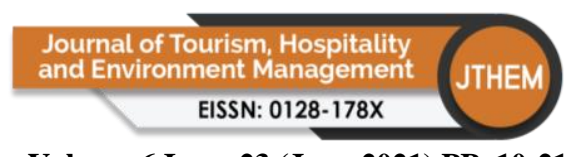

Volume 6 Issue 23 (June 2021) PP. 10-21

DOI 10/35631/JTHEM.623002

relationships between man and woman, consumption of drugs and alcohol, and place severe punishment as a deterrent.

Severe punishment creates fear, and people abstain from such activities. It is useful as the crime rate is 0.8 per 100,000 persons, putting KSA in those few countries where criminal activities are minimum (Saudi Vision 2030).

(Kaufmann, 2010) in his World Bank Policy Research paper developed Worldwide Governance Indicators (WGI), and it consists of six fundamental indicators of governance: Voice and Accountability, Political Stability and Absence of Violence/Terrorism, Government Effectiveness, Regulatory Quality, Rule of Law and Control of corruption. He provides a comparison of 213 country and territories and ranks each indicator and nations on a scale of 0 to 100 .

In 2018 (WGI), the top 50 countries/territories scored more than 430 points out of the total 600 at an average of 72, while in countries that rank between 51 to 100, their average score comes down to 50. KSA overall performance positioned it at $109^{\text {th }}$, with a score of $277 / 600$ at an average of 46. Two indicators in which it suffers most are Voice and accountability and Political stability and non-violence, where it scores only 5.91 and 28.57. The rest of the indicators are under acceptable limits and points to the excellent health of the country.

In the United Nations e-government survey 2018, KSA ranked $52^{\text {nd, }}$ well above the largest democratic country like India (96), and now it aims to be in the top five countries. The Global Competitiveness Report 2018 published by World Economic Forum gives $39^{\text {th }}$ Rank to KSA, and World Bank's Logistic Performance Index put KSA at 55 ${ }^{\text {th }}$ Rank (2018).

With its oil-rich resources, Saudi Arabia scores high on the rule of law, control over corruption and quality regulation, and results in an environment conducive to economic growth. It is already in the top 20 economies $\left(18^{\text {th }}\right.$ with Nominal GDP: $\$ 782.48$ billion and GDP (PPP) equal to $\$ 1.86$ trillion). Recent reforms to introduce Value Added Tax (VAT) and progressive labour laws now aim to align the economy with the rest of the economically developed countries finally increase the non-oil revenue.

\section{COVID-19 and Kingdom of Saudi Arabia}

As a centre of Islam, Saudi Arabia is always open for religious pilgrimage for all nationalities. Due to the epidemic, it is evident that it suffers enormously. Although the timely decision to suspend international and domestic pilgrimage and ban on international travel proves beneficial. Still, more than three lakhs are affected by the virus, and more than five thousand deaths show the level of deep suffering.

The huge expatriates' population living in close premises are more susceptible, in order to save living expenses they chose to share space with many and if one of them got affected it means the whole house of individual got affected as a result become a spreader. The Government identified the cause and took action on such premises to control the epidemic, but the big cities are still the worst affected by it.

The government focus on citizens welfare is visible in its approach to develop a health and education system. The Ministry of Health share of the total budget is $8.40 \%$ (Ministry of 


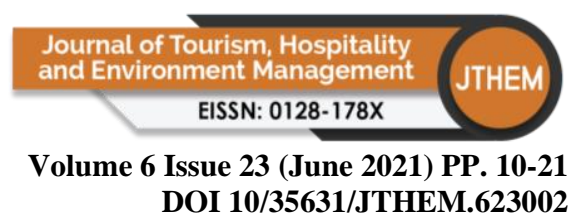

Health, 2019). The availability of 22.5 beds, 33.1 physicians and 58.2 nursing staff per 10,000 of the population shows government commitment towards their citizens. The developed health structure helps the Government handle the epidemic and strict measures like lockdown, including the two holiest sites (Mosier, Elhadary, Elhaty, \& and Safaei, 2020), a hefty fine on non-compliance of COVID guidelines, not to mention a well-structured and informative campaign to create awareness; because of this, less than six thousand deaths from more than three lakh infections.

The economic cost of COVID-19 is huge, besides the production lost and lost in revenue from the pilgrimage season and the low oil prices, force authorities to apply emergency measures. The 15\% VAT application on consumable items is one such measure. The availability of government wealth fund with fatty deposits is a blessing, and the Government is using it wisely by announcing various measures to fight COVID-19.

\section{Why Saudi Arabia Security, Stability and Reforms are Important for The World?}

KSA is one of the few countries where the crime rate is low, despite this Saudi Arabian image suffers due to extremist ideology adopted and propagated by few. The Government is making all efforts necessary to keep such elements under control and improve its image. The administration (Ahmed Osman Ibrahim, 2021) is on the right track as it opens its market for investment and promises them a secure internal environment and business-friendly policies.

Although regional turmoil the war in Yemen, sympathy for Muslim brothers suffering in many countries has a considerable impact on the social fabric and prepares the ground for extremist ideology to flourish, the Government is effectively curbing antisocial elements in addition to this showing concern for humanitarian issues besides a willingness to help the sufferers in resolving them. Government action is earning goodwill both internally and internationally, but to wash out its negative image, it needs time and more shreds of evidence to implement its vision successfully.

Saudi Arabia risk ratings in currency, banking and economics are currently low, but there is a possibility of change if the situation deteriorates. Most of the present export earnings are from oil, but the Government has initiated reforms to lessen its dependency. Meantime availability of sizeable sovereign wealth fund provides safety for government expenditure without facing any fiscal challenge.

Saudi Arabian prominence on social welfare is appreciable as it takes the responsibility of health and education expenses. Nevertheless, citizens do have the option to avail private sector facilities according to their convenience and income earnings.

\section{Conclusion}

The need for reforms felt due to low oil price shocks and roll out in Vision 2030. The Government realizes that present extravagant expenditure habits are only possible if they have income sources other than oil and gas. A strong economy is an indicator of a strong nation, too much dependence on sovereign wealth fund in years of price shock will prove costly in future. Secondly, it is crucial to keep investing in the educational, health and defence sector for a better tomorrow. 


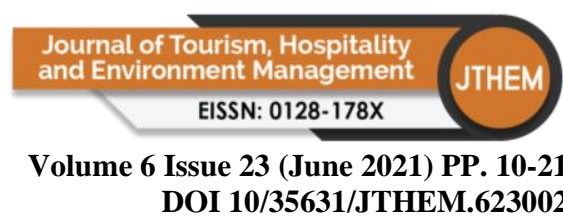

The move to push economic reforms centred around tourism should be appreciated. The Government move to welcome entertainment and adventure mixed cultural exchange could signal that as a centre of the Islamic world, they open the doors for others to see Saudi Arabian heritage furthermore invite well-known artists to market their reforms. Being at the centre of the Islamic world with the two holiest cities and annual pilgrimage Haj inviting millions of Muslims, the decision to develop tourism, where the Muslims around the world will not only convey the hospitality message of Saudi Arabia but also provide a boost to the economy is a strategic winner.

The social impact analysis of events is essential to determine the general population's acceptance level. Identifying the negative impact and controlling them at the initial level is most important. Social exchange theory and Growth machine theory are essential research to identify the social impact of large scale event and development of clusters (happy or unhappy) as it will bring social changes either in the form of resistance if the unhappy clusters are more in comparison to happy ones or support if the happy clusters are dominant in numbers.

The objective of reforms remains to increase economic activity, boost employment opportunities for Saudi citizens, and enhance living standards besides other economic benefits. Simultaneously, the Government wants to avoid any increase in crime level, disruption of peaceful life, and increased living costs. KSA is the Islamic centre, and Muslims worldwide observe the changes, and it will be a strategic blunder if the reforms are portrayed as a dilution in Islamic principles or surrendering to western influence.

With the complexity of having a religious society and Islamic centre, KSA needs to be extra vigilant and need to study even the minute changes in the society and requires careful planning to craft out events that bring the desired social outcome avoiding adverse outcomes.

The reforms and their associated promotional events hurt badly due to COVID-19. Since March 2020 , there are 341,495 cases inside KSA and 5144 deaths. The decisions to stop international flights, strict application of curfew, heavy penalties for persons seen breaking social distancing rules, and sufficient medical infrastructure to support and counter the epidemic are reasons that the Government can normalize life.

The decisions during COVID-19 has a substantial economic cost attached to them. The economy suffers on various fronts. The hotel industry lost one full season of Ramzan (The holy month) and Haj, in which only a few thousand people are allowed to perform Haj instead of millions who comes from outside. All those business activities associated with the annual pilgrimage also suffers deeply, as business activities need to be shut down due to lack of customers. Future social impact study should include the COVID period and cover how much the past event's influence remains on the population. The identification will help in continuation from the point, instead of starting the activity all over again.

\section{References}

Ahmed Osman Ibrahim, F. M. (2021, January ). Opting for Enriching Saudi Arabia's Tourism Attraction Sites towards the Realization of Vision 2030. International Journal on Innovations in Online Education, 20(5). doi:10.17051/ilkonline.2021.05.450

Ahmed, M. (2016). Nitaqat' Law: Labor Market Reforms in KSA and its Impact. Amity Journal of Management Research, 1(2), 44-51. Retrieved from https://amity.edu/UserFiles/admaa/3219116\%20Masood.pdf 


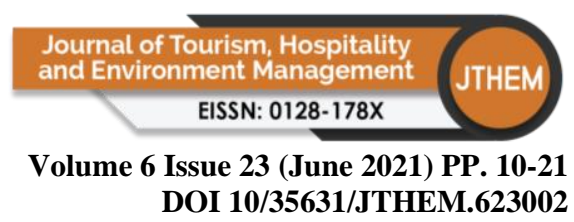

Algahtani, G. J. (2016). The Effect of Oil Prices Shocks on Economic Activity in Saudi Arabia: Econometric Approach. International Journal of Business and Management, 11(8). doi:10.5539/ijbm.v11n8p124

Eid, R. (2019). TOWARDS A HIGH-QUALITY RELIGIOUS TOURISM MARKETING: THE CASE OF HAJJ SERVICE IN SAUDI ARABIA. Tourism Analysis, 17, 509-522. doi:10.3727/108354212X13473157390849

Emerson, R. M. (1976). Social Exchange Theory. Annual Review of Sociology, 2, 335-362. Retrieved fromhttp://www.communicationcache.com/uploads/1/0/8/8/10887248/social_exchang e_theory-1976.pdf

Hassan, T. S.-D. (2020). THE SOCIAL RESPONSIBILITY OF TOURISM AND HOTEL ESTABLISHMENTS AND THEIR ROLE IN SUSTAINABLE TOURISM DEVELOPMENT IN AL-AHSA, SAUDI ARABIA. GeoJourrnall off Tourism and Geosiittes, 33(4), 1564-1570. doi:10.30892/gtg.334spll18--609

https://www.arabnews.com. (2020, Feb 05). Retrieved from Arab News: https://arab.news/2gymf

Ibrahim, A. \&. (2021, March). Tourism attraction sites: Boosting the booming tourism of Saudi Arabia. International Journal of ADVANCED AND APPLIED SCIENCES., 8(4). doi:10.21833/ijaas.2021.04.001

Jamel, L. (2020). The Relation between Tourism and Economic Growth: A Case of Saudi Arabia. Virtual Economics, 3(4). doi:https://doi.org/10.34021/ve.2020.03.04(2)

Kaufmann, D. a. (2010, September). The Worldwide Governance Indicators: Methodology and Analytical Issues. World Bank Policy Research Working Paper No. 5430. Retrieved from https://papers.ssrn.com/sol3/papers.cfm?abstract_id=1682130

Kraay, D. K. (2018). Worldwide Governance Indicators. Retrieved from worldbank.org: https://info.worldbank.org/governance/wgi/

Madrigal, R. (1995). Residents' perceptions and the role of Government. Annals of Tourism Research, 22(1), 86-102. Retrieved from https://doi.org/10.1016/0160-7383(94)000709

MaKinsey \& Company Report (2015, December). Retrieved from makinsey.com: https://www.mckinsey.com/featured-insights/employment-and-growth/moving-saudiarabias-economy-beyond-oil

Mansour, M., \& Mumuni, A. G. (2019). Motivations and attitudes toward domestic tourism in Saudi Arabia. EJTHR. Retrieved from https://doi.org/10.2478/ejthr-2019-0004

Ministry of Health, S. A. (2019). Government Publication. Retrieved from https://www.moh.gov.sa/en/Ministry/Statistics/book/Pages/default.aspx

Moliner, P. R. (2012). Social representation theory. In P. M.-C. Patrick Rateau, HANDBOOK OF THEORIES OF SOCIAL PSYCHOLOGY (pp. 477-497). London: Sage Publication Ltd.

Retrieved from https://lmsspada.kemdikbud.go.id/pluginfile.php/69497/mod_resource/content/3/Hand book\%20of\%20social\%20psychology.pdf

Mosier, W., Elhadary, T., Elhaty, I. A., \& and Safaei, M. (2020). Crisis Management and The Impact of Pandemics on Religious Tourism. International Journal of Religious Tourism and Pilgrimage, 8(7). Retrieved from https://arrow.tudublin.ie/ijrtp/vol8/iss 7/3

News, A. (2017). Hajj revenues poised to exceed $\$ 150$ bn by 2022. Arab News.

Nunkoo, R. (2016). Toward a More Comprehensive Use of Social Exchange Theory to Study Residents' Attitudes to Tourism. Procedia Economics and Finance, 588-596. 
Volume 6 Issue 23 (June 2021) PP. 10-21 DOI 10/35631/JTHEM.623002

Tarek Tawfik Yousef Alkhateeb, Z. A. (2017). Oil Revenue, Public Spending, Gross Domestic Product and Employment in Saudi Arabia. International Journal of Energy Economics and Policy, 7(6), 27-31. Retrieved from www.econjournals.com

Triki, M. B. (2019). THE ROLE OF RELIGIOUS TOURISM IN SUSTAINABLE DEVELOPMENT IN SAUDI ARABIA: EVIDENCE FROM QUANTILE NONCAUSALITY TEST. Geojournal of Tourism and Geosites. doi:10.30892/gtg.27417436

Vision 2030. Kingdom of Saudi Arabia. (n.d.). Retrieved from vision2030.gov.sa

World Development Indicators. (2020). Retrieved from World Bank: http://datatopics.worldbank.org/world-development-indicators/

Zhang, S. (2014). Land-centered urban politics in transitional China - Can they be explained by Growth Machine Theory? CITIES, 41, 179-186. doi:http://dx.doi.org/10.1016/j.cities.2014.02.010 